\title{
Karakteristik Tempat Tumbuh Palaquium spp Pada Areal Tembawang Dusun Lubuk Tapang ecamatan Ketungau Hulu Kabupaten Sintang Kalimantan Barat
}

\author{
Muhammad Syukur \\ Fakultas Pertanian Universitas Kapuas Sintang \\ Email : msyukur1973@yahoo.co.id
}

\begin{abstract}
Abstrak: Penelitian ini bertujuan untuk mengetahui karakteristik berupa vegetasi sekitar dan sifat fisika dan kimia tanah sebagai tempat tumbuh pohon Palaquium spp yang terdapat pada areal Tembawang dusun Lubuk Tapang Kecamatan Ketungau Hulu Kabupaten Sintang kalimantan Barat. Hasil penelitian ini diharapkan dapat menambah ilmu dan pengetahuan terutama mengenai karakteristik vegetasi sekitar dan sifat fisika dan kimia tanah sebagai tempat tumbuh pohon Palaquium spp yang terdapat pada areal Tembawang dusun Lubuk Tapang Kecamatan Ketungau Hulu Kabupaten Sintang Kalimantan Barat. Penelitian ini dilaksanakan dengan menggunakan metode petak tunggal. Penentuan petak pengamatan dilakukan secara purposive sampling (disengaja) pada areal yang terdapat banyak pohon Palaquium spp. Petak yang digunakan untuk pengamatan adalah petak tunggal yang berukuran $100 \mathrm{~m}$ x $60 \mathrm{~m}$. Didalam petak tunggal tersebut terdapat masing-masing 15 plot pengamatan untuk tingkat pohon, tiang, pancang dan semai.

Hasil penelitian diketahui bahwa terdapat 39 jenis vegetasi yang terdapat di sekitar pohon Palaquium spp yang terdiri atas 19 jenis pohon, 9 jenis Herba, 6 jenis Tumbuhan Bawah, 3 jenis Terna dan 2 jenis Liana. Tanah pada lokasi penelitian memiliki Karbon Organik sebesar 0,61\% (Sangat Rendah), N Total 0,09\% (Sangat Rendah), C/N rasio 6,78 \% (Rendah), K 0,08 (Sangat Rendah), Ca 0,39 (Sangat Rendah), Mg 0,17 (Sangat Rendah), P tersedia 12,76 (Rendah), KTK 11,50 (Rendah), KB 5,60 (Sangat Rendah), $\mathrm{pH} \mathrm{H}_{2} \mathrm{O}$ (Masam), Kadar Air 1,79\% (Rendah) dan tergolong tanah Debu/Lempung berpasir dan iklim yang sesuai bagi pertumbuhan Palaquium spp yaitu rata-rata curah hujan bulanan adalah $230 \mathrm{~mm}$, rerata suhu udara bulanan $23-33{ }^{\circ} \mathrm{C}$, rerata Kelembaban Relatif bulanan $86 \%$.

Kata Kunci : Karakteristik Tempat Tumbuh, Pohon Palaquium spp dan Areal Tembawang
\end{abstract}

\section{PENDAHULUAN}

Jenis Palaquium $s p$ termasuk kelompok jenis kayu perdagangan dari suku Sapotaceae. Di Indonesia terdapat sekitar 48 jenis dengan daerah persebaran dari Sumatera hingga Papua dan tumbuh di hutan dataran rendah hingga dataran tinggi mencapai ketinggian $1100 \mathrm{~m}$ dari permukaan laut.
Banyak jenis tumbuh di dataran rendah serta di hutan rawa air tawar dan hutan rawa gambut, kadang sepanjang sungai, jarang tumbuh di dataran tinggi.

Pada umumnya kayu Palaquium spp dimanfaatkan sebagai konstruksi rumah, bahan perahu, perabot rumah, pintu berukir, venir dan panel. Selain itu buah dan biji dapat dimakan, bijinya 
Karakteristik Tempat Tumbuh Palaquium spp Pada Areal Tembawang Dusun Lubuk Tapang ecamatan Ketungau Hulu Kabupaten Sintang Kalimantan Barat

dapat untuk membuat minyak goreng atau minyak padat, mentega, sabun dan minyak lampu penerang; getahnya disebut getah perca digunakan untuk bahan membuat bola golf, isolasi kabel listrik, pembalut pipa, dan untuk melindungi luka (Ibrahim, 2012).

Memahami dan mengetahui karakteristik tempat tumbuh suatu jenis tumbuhan menjadi sangat penting untuk kelangsungan/kelestarian jenis yang bersangkutan, begitu juga dengan jenis Palaquium spp. Pohon Palaquium spp secara teoritis tumbuh di seluruh wilayah Indonesia, dapat dijumpai/tumbuh pada tanah yang berpasir, rawa dan agak lembab. Walaupun demikian, masih tetap diperlukan deskripsi spesifik tempat tumbuh pada suatu daerah tertentu, tidak terkecuali habitat Palaquium spp yang terdapat pada areal Tembawang dusun Lubuk Tapang Kecamatan Ketungau Hulu Kabupaten Sintang Kalimantan Barat.

\section{METODOLOGI PENELITIAN}

\section{Metode Penelitian}

Metode yang digunakan dalam penelitian ini adalah metode petak tunggal. Penentuan petak pengamatan dilakukan secara purposive sampling (disengaja) pada areal yang terdapat banyak pohon Palaquium spp. Petak yang digunakan untuk pengamatan adalah petak tunggal yang berukuran 100 m x 60 m. Didalam petak tunggal tersebut terdapat masing-masing 15 plot pengamatan untuk tingkat pohon, tiang, pancang dan semai.

\section{Bahan dan Alat Penelitian}

Bahan-bahan yang digunakan dalam penelitian ini adalah semua jenis vegetasi berkayu tingkat semai, pancang, tiang dan pohon yang ditemukan dalam petak pengamatan serta sampel tanah pada lokasi penelitian. Adapun alat-alat yang digunakan dalam penelitian ini adalah Peta, GPS, Phiband, Parang, Kamera, Alat tulis/buku, kantong plastik dan lain-lain..

\section{Pelaksanaan Penelitian}

\section{Persiapan Penelitian}

Kegiatan persiapan meliputi pengumpulan alat dan bahan yang akan digunakan untuk penelitian, serta observasi lapangan untuk menentukan letak petak pengamatan.

\section{Penentuan Petak Pengamatan}

Penentuan petak pengamatan dilakukan dengan menggunakan metode purposive sampling, yaitu menempatkan petak pengamatan secara sengaja pada areal 
Karakteristik Tempat Tumbuh Palaquium spp Pada Areal Tembawang Dusun Lubuk Tapang ecamatan Ketungau Hulu Kabupaten Sintang Kalimantan Barat

yang terdapat banyak pohon Palaquium

spp. Petak yang digunakan untuk pengamatan adalah petak tunggal yang berukuran $100 \mathrm{~m}$ x $60 \mathrm{~m}$. Pada petak tunggal yang luasnya $100 \mathrm{~m} \mathrm{x} 60 \mathrm{~m}$ dibuat plot-plot pengamatan berukuran $20 \mathrm{~m} \times 20 \mathrm{~m}$ untuk tingkat pohon (trees) sebanyak 15 buah, ukuran $10 \mathrm{~m}$ x $10 \mathrm{~m}$ untuk tingkat tiang (poles) sebanyak 15 buah, $5 \mathrm{~m} \times 5 \mathrm{~m}$ untuk tingkat pancang (saplings ) sebanyak 15 buah, dan $2 \mathrm{~m} \times 2 \mathrm{~m}$ untuk tingkat semai (seedlings) sebanyak 15 buah. Bagan petak pengamatan dapat dilihat pada gambar berikut ini.

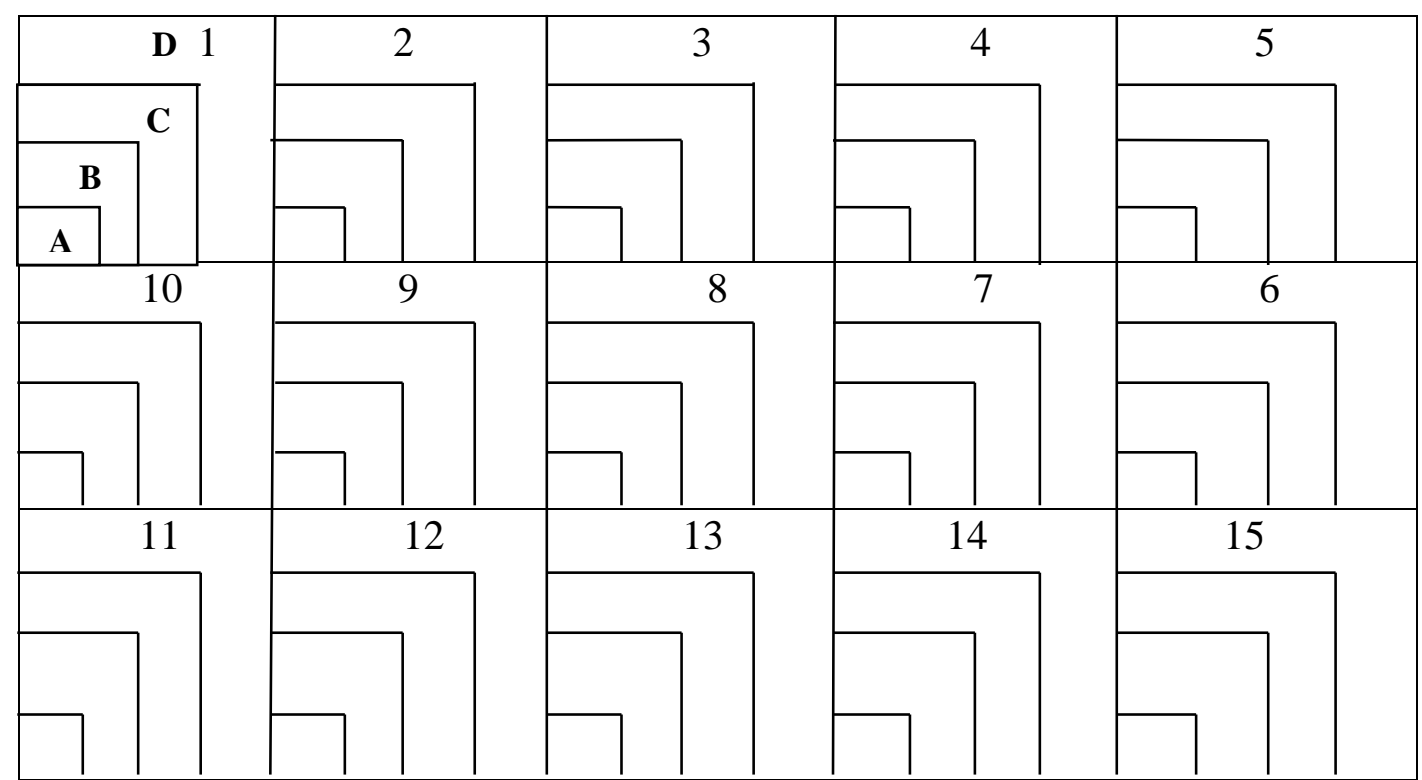

Gambar.1. Bentuk Petak Pengamatan.

Keterangan :

A : Petak $2 \times 2 \mathrm{~m}$, untuk tingkat semai (Seedlings) sebanyak 15 buah plot

B : Petak $5 \times 5$ m, untuk tingkat pancang (Saplings) sebanyak 15 plot

C : Petak $10 \times 10 \mathrm{~m}$, untuk tingkat tiang (Poles) sebanyak 15 plot

D : Petak 20 x 20 m, untuk tingkat pohon (Trees) sebanyak 15 plot

\section{Analisa Vegetasi}

Analisa vegetasi yaitu mengidentifikasi dan inventarisasi seluruh jenis tumbuhan tingkat semai sampai pohon yang berada disekitar pohon Palaquium spp. Jenis vegetasi yang terdapat pada petak pengamatan dicatat nama jenis, jumlah individu dan diameter batang (dicatat dalam tally sheet).

\section{Pengambilan Sampel Tanah}

Pengambilan sampel tanah dilakukan untuk pengamatan sifat fisika dan kimia tanah. Pengambilan sampel tanah di dalam petak pengamatan dilakukan secara purposive sampling pada 3 
Karakteristik Tempat Tumbuh Palaquium spp Pada Areal Tembawang Dusun Lubuk Tapang ecamatan Ketungau Hulu Kabupaten Sintang Kalimantan Barat

tempat dengan kedalaman $75 \mathrm{~cm}$ dari permukaan tanah, yaitu petak pengamatan nomor 1, 8 dan 15. Sampel tanah diambil dengan menggunakan pipa paralon dengan cara ditancapkan kedalam tanah. Tanah yang sudah diambil kemudian disimpan kedalam kantong plastik dan diberi label. Selanjutnya sampel tanah tersebut digabung menjadi satu, sehingga menjadi sampel komposite untuk kemudian dianalisis di Laboratorium

\section{HASIL DAN PEMBAHASAN}

\section{Hasil Penelitian}

Berdasarkan hasil analisia vegetasi pada petak pengamatan diketahui bahwa terdapat 39 jenis vegetasi yang terdapat di sekitar pohon Palaquium spp. Hasil analisa vegetasi diketahui bahwa vegetasi yang terdapat di sekitar pohon Palaquium spp di dominasi oleh jenis pohon sebanyak 19 jenis, 9 jenis Herba, 6 jenis Tumbuhan Bawah, 3 jenis Terna dan 2 jenis Liana. Terdapat beberapa pohon yang memiliki nilai komersil cukup tinggi seperti Tembawang, Empilik, Lukai, Mentawak dan Berangan. Jenis-jenis vegetasi sekitar pohon Palaquium spp selengkapnya dapat dilihat pada tabel berikut ini

Tabel 1. Jenis-Jenis Vegetasi Sekitar Palaquium spp

\begin{tabular}{|c|c|c|c|c|}
\hline No & Jenis & Nama Ilmiah & Famili & Habitus \\
\hline$\underline{1}$ & Asam Pelam & Mangifera sp & Anacardiaceae & Pohon \\
\hline$\underline{2}$ & Asam Kandis & $\begin{array}{l}\text { Garcinia } \\
\text { xanthochymus }\end{array}$ & Clusiaceae & $\overline{\text { Pohon }}$ \\
\hline$\underline{3}$ & $\underline{\text { Bambu }}$ & Bambusa sp & Poaceae & Terna \\
\hline$\underline{4}$ & Bedaup & $\begin{array}{l}\text { Cantleya } \\
\text { corniculata }\end{array}$ & Stemonuraceae & Terna \\
\hline$\underline{5}$ & Berangan & $\begin{array}{l}\text { Castanopsis } \\
\text { inermis }\end{array}$ & Fagaceae & Pohon \\
\hline$\underline{6}$ & Berenai & Crescentia cujete & Bignoniaceae & Pohon \\
\hline$\underline{7}$ & Cempedak & $\frac{\text { Artocarpus }}{\text { cempedens }}$ & Moraceae & Pohon \\
\hline$\underline{8}$ & Cerengak & Dipterocarpus spp & Dipterocarpaceae & Pohon \\
\hline$\underline{\overline{9}}$ & Empedu Sawak & Derris sp ${ }^{1}$ & Fabaceae & $\underline{\text { Liana }}$ \\
\hline$\underline{10}$ & Empilik & $\overline{\text { Quercus sp }}$ & Fagaceae & $\overline{\text { Pohon }}$ \\
\hline$\underline{11}$ & Empukak & Neyraudia $s p$ & Poaceae & Tumbuhan Bawah \\
\hline$\underline{12}$ & Engkerebang & Pterocarpus sp & Papilionaceae & Herba \\
\hline
\end{tabular}


Karakteristik Tempat Tumbuh Palaquium spp Pada Areal Tembawang Dusun Lubuk Tapang ecamatan Ketungau Hulu Kabupaten Sintang Kalimantan Barat

\begin{tabular}{|c|c|c|c|c|}
\hline 13 & Ensubal & Eugenia sp ${ }^{1}$ & Myrtaceae & Herba \\
\hline 14 & Gerenih & Paspalum sp & Poaceae & Tumbuhan Bawah \\
\hline$\overline{15}$ & Gumba & Hopea sp & Dipterocarpaceae & Pohon \\
\hline 16 & Kabu & Ceiba pentandra & Malvaceae & Pohon \\
\hline$\underline{17}$ & Kayu Malam & Diospyros sp & Ebenaceae & Pohon \\
\hline$\underline{18}$ & Kelinduk & Melastoma $s p$ & Melastomataceae & Tumbuhan Bawah \\
\hline$\underline{19}$ & Kubal & Typhonium sp & Araceae & Herba \\
\hline$\underline{\underline{20}}$ & Kumis Babi & Orthosiphon $s p$ & Lamiaceae & Herba \\
\hline 21 & Kumpang & Myristica sp & MMyristicaceae & Herba \\
\hline$\underline{22}$ & Lambir Tiung & Wedelia $s p$ & Asteraceae & Herba \\
\hline 23 & Langkung Noba & Dryobalanops $s p^{1}$ & Dipterocarpaceae & Pohon \\
\hline$\overline{24}$ & Lemak Beruk & Dryobalanops $s p^{2}$ & Dipterocarpaceae & $\overline{\text { Pohon }}$ \\
\hline 25 & Lembak & Gardenia & Rubiaceae & Tumbuhan Bawah \\
\hline$\underline{\underline{26}}$ & Lengkan & Derris sp ${ }^{2}$ & Fabaceae & Liana \\
\hline$\underline{27}$ & Lukai & & & Pohon \\
\hline$\underline{28}$ & Mentawak & $\frac{\text { Artocarpus }}{\text { lanceifolius }}$ & Moraceae & $\overline{\text { Pohon }}$ \\
\hline$\underline{29}$ & $\underline{\text { Pensik }}$ & Tristaniopsis $\mathrm{sp}$ & Myrtaceae & Pohon \\
\hline$\underline{\underline{30}}$ & Peru & Mimosa sp & Mimoceae & Herba \\
\hline$\underline{31}$ & $\overline{\text { Purang }}$ & Cratoxylon sp & $\overline{\text { Guttiferae }}$ & Pohon \\
\hline$\underline{32}$ & Ribu & Altermanthera sp & Asteraceae & Herba \\
\hline$\underline{33}$ & Ridan & Oplismenus sp & Poaceae & Terna \\
\hline 34 & Senggang & Alpinia sp & Zingiberaceae & Herba \\
\hline$\overline{35}$ & Sirih Remaung & Piper sp & Piperaceae & $\overline{\text { Tumbuhan Bawah }}$ \\
\hline$\underline{\underline{36}}$ & Tambun & Phyllantus sp & Euphorbiaceae & Tumbuhan Bawah \\
\hline$\underline{37}$ & Tembawang & Shorea $s p$ & Dipterocarpaceae & Pohon \\
\hline$\underline{38}$ & Ubah & Eugenia sp ${ }^{2}$ & Myrtaceae & $\overline{\text { Pohon }}$ \\
\hline$\underline{39}$ & Ucung Tikus & Eugenia sp & Myrtaceae & Pohon \\
\hline
\end{tabular}

Berdasarkan hasil analisis tanah yang dilakukan pada Laboratorium, diketahui bahwa tanah sebagai tempat tumbuh pohon Palaquium spp di lokasi penelitian dapat dilihat pada tabel berikut ini.

Tabel 2. Hasil Analisis Tanah Sebagai Habitat Pohon Nyatoh dan Kriteria Penilaian Berdasarkan Pusat Penelitian Tanah Bogorertambahan Jumlah Daun Anakan Tekam

\begin{tabular}{|c|c|c|c|}
\hline No & Parameter & Hasil Analisis & $\begin{array}{c}\text { Kriteria Penilaian PPT } \\
\text { Bogor }\end{array}$ \\
\hline 1 & Karbon Organik (\%) & $\underline{0,61}$ & Sangat Rendah \\
\hline$\underline{2}$ & Nitrogen $(\%)$ & $\overline{0,09}$ & $\overline{\text { Sangat Rendah }}$ \\
\hline$\underline{3}$ & C/N Rasio (\%) & $\overline{6,78}$ & Rendah \\
\hline$\underline{4}$ & P-Tersedia (ppm) & 12,76 & Rendah \\
\hline$\underline{5}$ & $\mathrm{KTK}(\mathrm{C} \mathrm{mol} / \mathrm{Kg})$ & $\underline{11,50}$ & Rendah \\
\hline$\underline{6}$ & $\underline{\text { Kalium }(\mathrm{C} \mathrm{mol} / \mathrm{Kg})}$ & $\underline{0,08}$ & $\underline{\text { Sangat Rendah }}$ \\
\hline$\underline{\bar{z}}$ & Kalsium (C mol/Kg) & $\underline{\underline{0,39}}$ & $\overline{\text { Sangat Rendah }}$ \\
\hline
\end{tabular}


Karakteristik Tempat Tumbuh Palaquium spp Pada Areal Tembawang Dusun Lubuk Tapang ecamatan Ketungau Hulu Kabupaten Sintang Kalimantan Barat

\begin{tabular}{|c|c|c|c|}
\hline$\underline{8}$ & Magnesium $(\mathrm{C} \mathrm{mol} / \mathrm{Kg})$ & $\underline{0,17}$ & Sangat Rendah \\
\hline$\underline{9}$ & $\mathrm{~KB}(\%)$ & $\underline{\underline{5,60}}$ & Sangat Rendah \\
\hline 10 & Clay/Liat (\%) & 22,75 & Tanah Debu/Lempung \\
\hline 11 & Silt/Debu (\%) & 48,35 & Berpasir \\
\hline$\underline{12}$ & F.Sand/Pasir Kasar (\%) & 23,01 & \\
\hline$\underline{13}$ & C.Sand/Pasir Halus (\%) & $\underline{5,89}$ & \\
\hline$\underline{14}$ & Kadar Air (\%) & $\underline{1,79}$ & Rendah \\
\hline$\underline{15}$ & $\mathrm{pH} \mathrm{H}{ }_{2} \mathrm{O}$ & 4,67 & Masam \\
\hline
\end{tabular}

Sumber : Hasil Penelitian, 2017

\section{Pembahasan}

Hasil diketahui bahwa terdapat 39 jenis vegetasi yang terdapat di sekitar pohon Palaquium spp. Jenis-jenis yang dominan terdapat pada lokasi penelitian adalah Tembawang, Empilik, Purang dan tumbuhan bawah maupun herba serta terna. Jenis- jenis tersebut dari sudut ekologis menggambarkan bahwa keadaan pada lokasi penelitian cukup baik dan belum mengalami gangguan. Asumsi ini diperkuat oleh keadaan di lapangan dan hasil analisis yang menunjukkan bahwa jenis pohon yang paling dominan bukan dari jenis pohon pioner. Kondisi yang baik ini merupakan tempat tumbuh yang dikehendaki/sesuai bagi jenis-jenis dari pohon tersebut, sekaligus sebagai indikator belum terganggunya tempat tumbuh. Kondisi ini menunjukkan pohon Palaquium spp yang merupakan tumbuhan asli yang tersebar di seluruh Indoneia. Jenis ini tumbuh pada tanah berawa dan sebagian pada tanah kering, dengan jenis tanah liat atau berpasir, di daerah banyak hujan pada ketinggian 20-500 meter di atas permukaan laut. Pohon Palaquium spp menghendaki tempat tumbuh dengan Ketinggian < 1300 meter dari permukaan laut, curah hujan berkisar antara $2000-4000$ $\mathrm{mm} /$ tahun, temperatur antara $18-30{ }^{\circ} \mathrm{C}$ dengan tanah yang teksturnya ringan sampai sedang. Palaquium spp dapat tumbuh dengan baik pada tanah dengan keasaman $(\mathrm{pH})$ asam sampai netral, drainase yang baik dan toleran terhadap naungan atau termasuk jenis yang tumbuhan intoleran. Kesesuaian tempat tumbuh inilah yang menyebabkan pohon Nyatoh tumbuh dengan sangat baik (memiliki batang yang cukup besar) pada lokasi peneilitian.

Hasil Analisis tanah pada lokasi tempat tumbuh Palaquium spp jika dibandingkan dengan kriteria tanah menurut PPT Bogor (1983) diketahui bahwa tanah pada lokasi penelitian memiliki Karbon Organik dan Nitrogen 
Karakteristik Tempat Tumbuh Palaquium spp Pada Areal Tembawang Dusun Lubuk Tapang ecamatan Ketungau Hulu Kabupaten Sintang Kalimantan Barat

tergolong sangat rendah, $\mathrm{C} / \mathrm{N}$ rasio rendah, Posfor (P tersedia) rendah, kalium sangat rendah, Kalsium dan Magnesium tergolong sangat rendah. Berdasarkan kajian teoritis tanah yang terdapat pada lokasi penelitian memiliki tingkat kesesuaian yang cukup baik bagi pertumbuhan pohon Palaquium spp, sehingga tumbuhan ini akan tumbuh secara optimal. Secara fisik berdasarkan hasil analisis terhadap sampel tanah, tanah pada lokasi penelitian dapat digolongkan sebagai tanah debu/lempung liat berpasir yang memang sangat baik untuk menopang pertumbuhan pohon Palaquium spp karena jenis ini dapat tumbuh dan berkembang dalam kondisi tempat tumbuh yang kurang baik. Hal ini sesuai dengan pendapat Ibrahim (2012), yang menyatakan bahwa di Indonesia terdapat sekitar 48 jenis pohon Palaquium spp dengan daerah persebaran dari Sumatra hingga Papua dan tumbuh di hutan dataran rendah hingga dataran tinggi mencapai ketinggian $1100 \mathrm{~m}$ dpl. Banyak jenis tumbuh di dataran rendah serta di hutan rawa air tawar dan hutan rawa gambut, kadang sepanjang sungai, jarang tumbuh di dataran tinggi. Kondisi ini terlihat jelas pada lokasi penelitian yang umumnya tanahnya berwarna cukup terang (alluvial) bercampur pasir.

Kondisi iklim yang terdapat pada lokasi penelitian merupakan keadaan yang ideal bagi tumbuh dan berkembangnya jenis-jenis tumbuhan di daerah tropis, begitu juga dengan pohon Palaquium spp. Suhu, kelembaban dan curah hujan pada lokasi penelitian semuanya sangat sesuai bagi poohon Palaquium spp untuk tumbuh dan berkembang dengan optimal, sehingga pertumbuhannya dapat maksimal yang ditunjukkan dengan besarnya diameter batang dan tinggi pohonnya.

\section{PENUTUP}

\section{Kesimpulan}

Berdasarkan hasil penelitian dan pengamatan, maka dapat disimpulkan sebagai berikut;

1. Terdapat 39 jenis vegetasi yang terdapat di sekitar pohon Palaquium spp yang terdiri atas 19 jenis pohon, 9 jenis Herba, 6 jenis Tumbuhan Bawah, 3 jenis Terna dan 2 jenis Liana.

2. Tanah pada lokasi penelitian memiliki Karbon Organik sebesar 0,61 \% (Sangat Rendah), N Total $0,09 \%$ (Sangat Rendah), C/N rasio 
Karakteristik Tempat Tumbuh Palaquium spp Pada Areal Tembawang Dusun Lubuk Tapang ecamatan Ketungau Hulu Kabupaten Sintang Kalimantan Barat

$6,78 \%$ (Rendah), K 0,08 (Sangat

Rendah), Ca 0,39 (Sangat Rendah),

Mg 0,17 (Sangat Rendah), P tersedia

12,76 (Rendah), KTK 11,50

(Rendah), KB 5,60 (Sangat Rendah),

pH $\mathrm{H}_{2} \mathrm{O}$ (Masam), Kadar Air 1,79\%

(Rendah) dan tergolong tanah

Debu/Lempung berpasir dan iklim yang sesuai bagi pertumbuhan

Palaquium spp yaitu rata-rata curah

hujan bulanan adalah $230 \mathrm{~mm}$, rerata

suhu udara bulanan $23-33{ }^{\circ} \mathrm{C}$, rerata

Kelembaban Relatif bulanan $86 \%$.

\section{Saran}

Areal Tembawang adalah bentuk kearifan lokal yang sampai saat ini terbukti mampu menjaga dan menjamin kelestarian keanekaragaman jenis hayati. Oleh karena itu perlu dukungan dan komitmen dari pemerintah untuk memperkuat kelembagaan yang dimiliki desa dalam menjaga kelestarian areal Tembawang, sehingga kelestarian keanekaragaman hayati juga dapat terjamin.

\section{DAFTAR PUSTAKA}

A. Ibrahim, 2012. Jenis Kayu Komersil Indonesia. http://www.horizon-customhomes.com.

Hardjowigeno, S. 1987. Ilmu Tanah. Edisi Baru. Akademika Pressindo. Jakarta.

Hyne, K., 1987. Tumbuhan Berguna Indonesia III. Departemen Kehutanan. Hal 1630-1634

Liemens, RHMJ., Soreianegara, I., Wong, WC., 1995. Minor Comersial Timber. Plant Resources of South East Asia. Timber Forest, Bogor Indonesia.

MacKinnon, Gusti Hatta, Hakimah Halim dan Arthur Mangalik. 2000. Ekologi Kalimantan. Seri ekologi Indonesia Buku III. Prenhallindo. Jakarta.

Odum.E.P. 1993. Fundamental of Ecology, Edisi Kedua, W. B. Solunder Company, Philadelphia Samingan, T. 1986. Tipe-tipe Vegetasi. Universitas Gadjah Mada. Yogyakarta.

Simon, H. 1990. Pengantar Ilmu Kehutanan. Fakultas Kehutanan. Universitas Gadjah Mada, Yogyakarta.

Soerianegara, I. dan Indrawan, A. 1980. Ekologi Hutan Indonesia. Fakultas Kehutanan IPB. Bogor. Winarto, B. 2006. Kamus Rimbawan. Yayasan Bumi Indonesia Hijau. Jakarta. 